\title{
Reliability Improvement and Remaining Issues on Photovoltaic Cells and Modules
}

\author{
Atsushi Masuda \\ Niigata University, Niigata 950-2181, Japan
}

\begin{abstract}
Degradation phenomena of photovoltaic cells and modules were systematically and in detail studied by observing those exposed outdoors and subjecting those to various indoor acceleration tests. Those degradation phenomena were roughly classified into three categories; less incident light into photovoltaic cells, less collection of photogenerated carriers, and less photovoltaic ability itself. Degradation mechanisms of photovoltaic cells and modules were clarified by microscopic physical and chemical analyses. Based on the mechanisms, it was found that key materials for improving reliability are encapsulants and electrodes. Improvement methods of reliability for photovoltaic cells and modules were also proposed. Prediction of lifetime by indoor acceleration test methods is also important although the prediction is quite difficult using the artificial test methods with only one or two degradation factor(s). Remaining issues of reliability and durability will be also presented.
\end{abstract}

\section{Introduction}

Worldwide rapid growth of photovoltaics requires not only high-efficiency but also highreliability and long-lifetime photovoltaic cells and modules. Reliability of photovoltaic modules is determined by module materials such as encapsulant, backsheet, edge sealant, pottant, interconnector ribbons, etc. and, of course, also by photovoltaic cells themselves. There are some complicated phenomena concerning degradation of photovoltaic properties. Those degradation phenomena should be microscopically analyzed in detail using physical and chemical methods in order to clarify degradation mechanism and also realize highly reliable photovoltaic cells and modules. Development of novel indoor acceleration test methods for exactly predicting lifetime is also important. However, it is very difficult to estimate the lifetime, even though the degradation mechanism is clearly understood. The reason is that many degradation factors are simultaneously given to photovoltaic modules exposed outdoors although only one or two, at the most, degradation factor(s) are given to photovoltaic modules in the acceleration test. In this paper, after brief introduction of both classification of degradation phenomena and acceleration test methods, key materials for improving reliability of photovoltaic cells and modules are discussed. Finally, remaining issues to be solved in the photovoltaic module science field are shown. 


\section{Classification of Degradation Phenomena}

Although degradation phenomena in photovoltaic cells and modules are complicated and often related with each other, degradation mechanism is simply classified into only three categories; 1) less incident light into photovoltaic cells, 2) less collection of photogenerated carriers, and 3) less photovoltaic ability itself. Less incident light often originates from soiling of cover glass; however, in some cases originates from browning, yellowing or discoloration of encapsulant or reduction of transparent conductive oxide electrodes (1,2). Less correction of carriers originates from damage of Ag finger electrodes on the cell or damage of interconnector ribbons between the cells. The former often occurs due to chemical corrosion by acetic acid generated by hydrolysis reaction between infiltrated water vapor and ethylene vinyl acetate (EVA) copolymer encapsulant (3-5) or breakage at intersections of Ag finger and busbar electrodes by thermal and mechanical stresses. Cell breakage, of course, also causes electrode breakages. The latter often occurs by thermal and mechanical stresses (6). Less photovoltaic ability originates from surface or bulk recombination or shunting. Such phenomena originate from potential difference between photovoltaic cells and grounded module frames made of $\mathrm{Al}$, and are often called potential-induced degradation (PID) $(7,8)$. Degradation phenomena in the first and the second categories are not accompanied with degradation in pn junction. On the other hand, shunt-type degradation phenomena in the third category originates from degradation in pn junction. These three categories are schematically shown in Figure 1.

There are various degradation factors, for example, thermal or mechanical stress, high temperature, high humidity, UV irradiation, and potential difference. In particular, hygrothermal stress, UV irradiation, potential difference, and also their combination are considerable factors. For example, UV irradiation accelerates degradation by hygrothermal stress (9), on the other hand, delays degradation by potential difference (10). It was also found that hygrothermal stress accelerates the degradation by potential difference (11). Figure 2 shows materials and components used in photovoltaic modules and also degradation factors.

\section{Prediction of Lifetime by Acceleration Test}

Both development of indoor acceleration test method and estimation of acceleration factor are also important for predicting the lifetime of photovoltaic modules. Although certification indoor test methods are regulated in IEC 61215 series, such tests only detect the possibilities of initial failures and cannot be used for lifetime prediction. As mentioned above, although UV light irradiation much influences degradation phenomena, test method using UV light irradiation is not popular. The reason is that it is quite difficult to keep the module temperature under irradiation during test duration and also to realize uniform irradiation for large-size photovoltaic modules over $1.5 \mathrm{~m}$. However, using acetic acid concentration in the EVA encapsulant as the mediator between outdoor exposure and indoor acceleration test, it was elucidated that damp heat test at $85^{\circ} \mathrm{C}$ and $85 \%$ relative humidity for 4000 h corresponds to outdoor exposure at Japan for 30 years (12). 


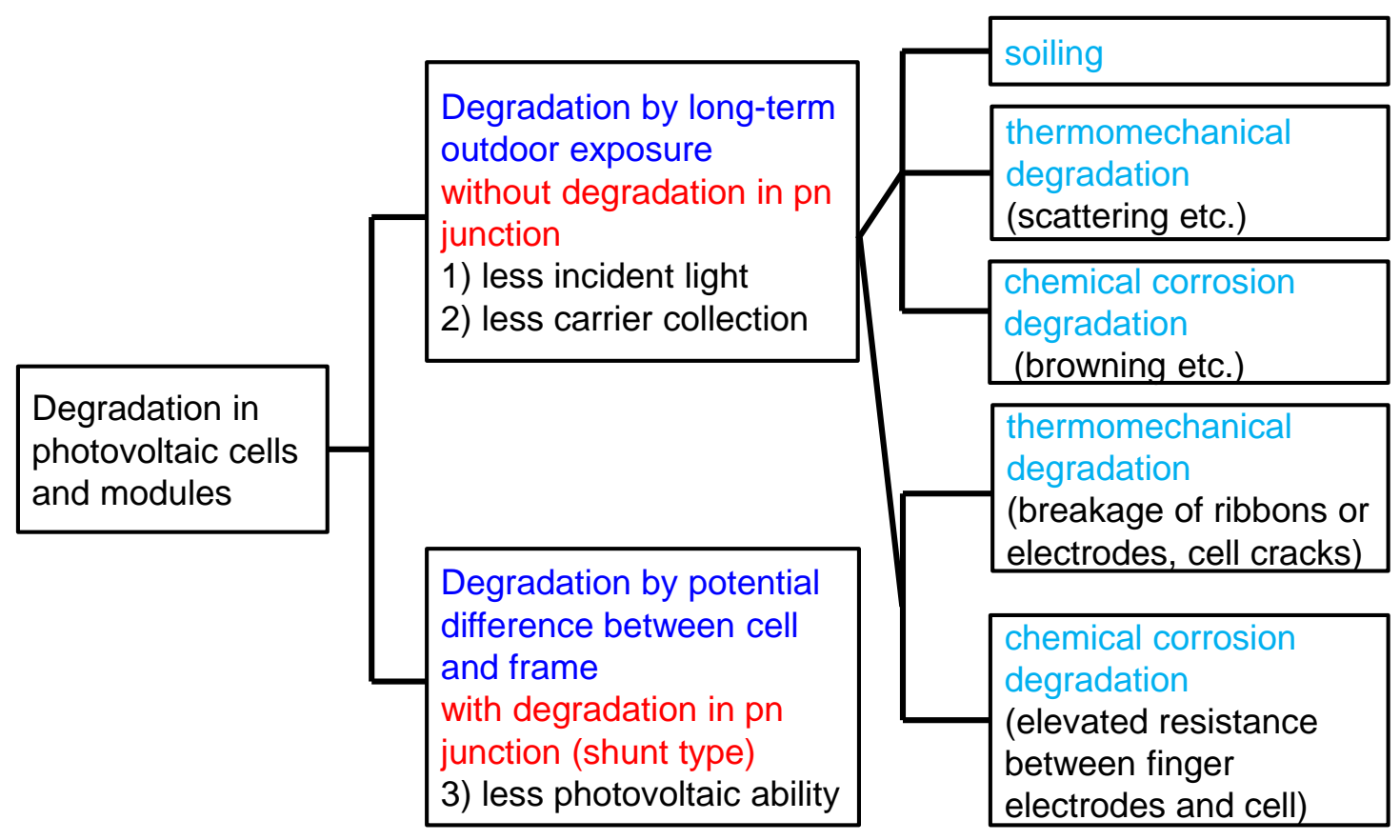

Figure 1. Classification of degradation phenomena in photovoltaic cells and modules.

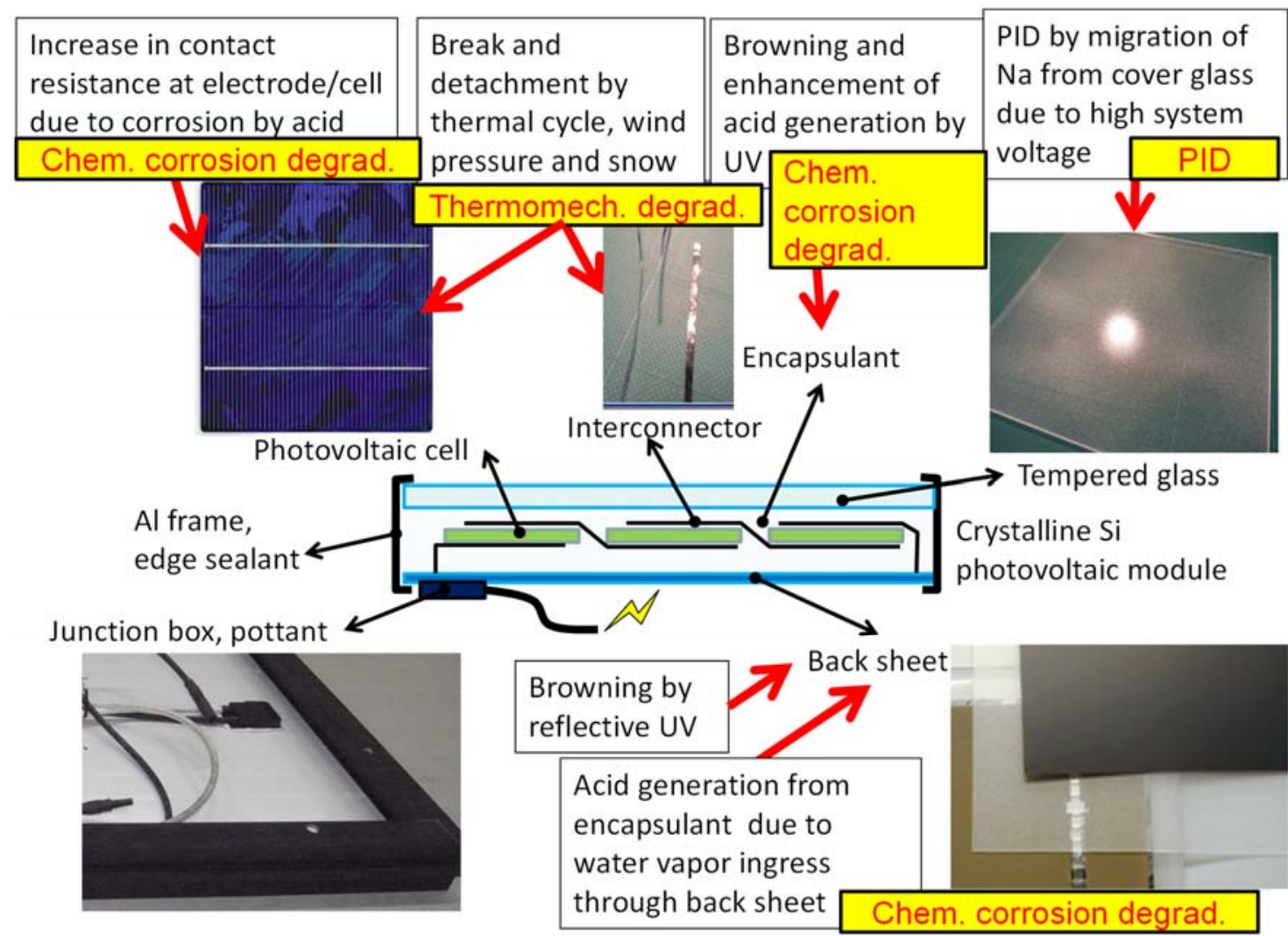

Figure 2. Schematic diagram of materials and components used in photovoltaic modules and also degradation factors. 


\section{Key Materials for Improved Reliability}

Based on degradation mechanism clarified, highly reliable photovoltaic cells and modules should be developed. It was elucidated that important key materials for high reliability are encapsulants and cell electrodes. It was shown that olefin and ionomer are candidates for highly reliable encapsulant materials, possibly taking the place of EVA. Those encapsulants generate less acid causing chemical corrosion of Ag finger electrodes and also less PID $(13,14)$. However, the most important key materials are cell electrodes. Even when photocarriers are generated, if damage or degradation occurs in the electrodes, such carriers are not collected and photovoltaic performance is lowered. Problems in photocarrier collection occupy majority of origins for degradation observed outdoors. Recently developed Ag electrode materials much delay degradation by acetic acid (5). Degradation by potential difference has also attracted much attention in the last 10 years especially in mega-watt scale photovoltaic plant with high system voltage. Encapsulants, as mentioned above, and anti-reflection coating of photovoltaic cells $(15,16)$ are key materials for suppressing such kinds of degradation.

\section{Remaining Issues and Conclusions}

There are some remaining issues on the photovoltaic module science field for improving reliability and increasing lifetime. First, interaction between module materials and cells should be completely clarified. Photovoltaic modules are composed of various materials including polymers, metals, ceramics, and, of course, semiconductors. Complicated reactions should occur both at the interface and in the bulk of those materials by many stressors such as high temperature, high humidity, thermal cycle, UV irradiation, potential difference, and the combination of some those stressors. Many observations and knowledges have been obtained so far, however, we do not reach the complete understanding, and essential point is that materials with less change and less interaction with other materials should be employed. Second, acceleration test results should be always analyzed with considering outdoor exposure results. Especially, climate conditions such as desert, tropical zone, etc. for outdoor exposure also should be employed for acceleration test conditions. Photovoltaic cells and modules appropriate to specific climate conditions should be developed. Third, high efficiency photovoltaic cells and modules should be developed always with considering high reliability and long lifetime. Those are inseparable issues for development of photovoltaic cells and modules. Especially, reliability issues on high-efficiency perovskite cells and modules should be intensively studied and urgently solved for realizing high efficiency and highly stable perovskite/silicon tandem cells and modules.

\section{Acknowledgments}

The author is grateful to Professors Keisuke Ohdaira, Sachiko Jonai, Yasuaki Ishikawa, Yasushi Sobajima, Fumitaka Ohashi, Kentaro Iwami, Dr. Seira Yamaguchi, Mr. Yasushi Tachibana, and Ms. Yukiko Hara for their collaboration and fruitful discussion. This study was in part supported by the New Energy and Industrial Technology Development Organization. 


\section{References}

1. S. Yamaguchi, C. Yamamoto, K. Ohdaira, and A. Masuda, Sol. Energy Mater. Sol. Cells, 161, 439 (2017).

2. S. Yamaguchi, C. Yamamoto, K. Ohdaira, and A. Masuda, Prog. Photovolt., 26, 697 (2018).

3. M. D. Kempe, G. J. Jorgensen, K. M. Terwilliger, T. J. McMahon, C. E. Kennedy, and T. T. Borek, Sol. Energy Mater. Sol. Cells, 91, 315 (2007).

4. C. Peike, T. Kaltenbach, K.-A. Weiß, and M. Koehl, Sol. Energy Mater. Sol. Cells, 95, 1686 (2011).

5. A. Masuda and Y. Hara, Jpn. J. Appl. Phys., 57, 04FS06 (2018).

6. S. Suzuki, T. Doi, A. Masuda, and T. Tanahashi, Jpn. J. Appl. Phys., 57, 02CE05 (2018).

7. R. Swanson, M. Cudzinovic, D. DeCeuster, V. Desai, J. Jürgens, N. Kaminar, W. Mulligan, L. Rodrigues-Barbosa, D. Rose, D. Smith, A. Terao, and K. Wilson, Tech. Dig. 15th Int. Photovoltaic Science and Engineering Conf., 2005, p. 410.

8. P. Hacke, M. Kempe, K. Terwilliger, S. Glick, N. Call, S. Johnston, S. Kurtz, I. Bennett, and M. Kloos, Proc. 25th European Photovoltaic Solar Energy Conf. Exhib./5th World Conf. Photovoltaic Energy Conversion, 2010, p. 3760.

9. T. Ngo, Y. Heta, T. Doi, and A. Masuda, Jpn. J. Appl. Phys., 55, 052301 (2016).

10. D. C. Nguyen, Y. Ishikawa, S. Jonai, K. Nakamura, A. Masuda, and Y. Uraoka, Sol. Energy, 199, 55 (2020)

11. A. Masuda, C. Yamamoto, Y. Hara, S. Jonai, Y. Tachibana, T. Toyoda, T. Minamikawa, S. Yamaguchi, and K. Ohdaira, Jpn. J. Appl. Phys., 59, 076503 (2020).

12. A. Masuda, S. Suzuki, Y. Hara, S. Sakamoto, and T. Doi, Proc. 29th European Photovoltaic Solar Energy Conf. Exhib., 2014, p. 2566.

13. C. G. Reid, S. A. Ferrigan, J. I. F. Martínez, and J. T. Woods, Proc. 28th European Photovoltaic Solar Energy Conf. Exhib., 2013, p. 3340.

14. J. Kapur, K. M. Stika, C. S. Westphal, J. L. Norwood, and B. Hamzavytehrany, IEEE J. Photovolt., 5, 219 (2015).

15. H. Nagel, A. Metz, and K. Wangemann, Proc. 26th European Photovoltaic Solar Energy Conf. Exhib., 2011, p. 3107.

16. S. Jonai, K. Nakamura, and A. Masuda, Appl. Phys. Express, 12, 101003 (2019). 